\title{
Oral nifedipine versus intravenous labetalol for acute blood pressure control in hypertensive emergencies of pregnancy: a randomized controlled trial
}

\author{
Anjuman Alam*, S. M. A. Zakaria \\ Department of Obstetrics and Gynecology, Assam Medical College and Hospital, Dibrugarh, Assam, India \\ Received: 09 February 2019 \\ Accepted: 06 March 2019 \\ *Correspondence: \\ Dr. Anjuman Alam, \\ E-mail: dr.anjuman.alam@gmail.com \\ Copyright: () the author(s), publisher and licensee Medip Academy. This is an open-access article distributed under \\ the terms of the Creative Commons Attribution Non-Commercial License, which permits unrestricted non-commercial \\ use, distribution, and reproduction in any medium, provided the original work is properly cited.
}

\begin{abstract}
Background: To compare intravenous labetalol with oral nifedipine in terms of rapidity at which they control blood pressure in acute hypertensive emergencies of pregnancy.

Methods: A randomized controlled study. Pregnant women with severe gestational hypertension with BP $\geq 160 / 110$ $\mathrm{mmHg}$ after $\geq 20$ weeks of gestation were randomized with computer generated numbers, either to receive IV labetalol with an escalating dose of $20,40,80,80$ and $80 \mathrm{mg}$ or nifedipine capsule orally in a dose of $10 \mathrm{mg}$ every 15 minutes (upto 5 doses) until a BP of $\leq 150 / 100 \mathrm{mmHg}$ is achieved. Crossover treatment was to be effected if initial treatment regimen was unsuccessful. Primary outcome was time taken and number of doses required to achieve the target BP of $\leq 150 / 100 \mathrm{mmHg}$. Secondary outcomes were volume of urine output, maternal heart rate changes, fetal heart rate abnormality, perinatal and maternal outcome and side effects.

Results: Oral nifedipine achieved the target BP $(\leq 150 / 100 \mathrm{mmHg})$ more rapidly in $(26.25 \pm 12.60)$ minutes in comparison to $(32.62 \pm 12.19)$ minutes with IV labetalol $(\mathrm{p}=0.024)$. Nifedipine group also took less number of doses to achieve the target $\mathrm{BP}$ of $(\leq 150 / 100 \mathrm{mmHg}) \mathrm{mmHg}$ than IV labetalol $(1.75 \pm 0.840 \mathrm{vs} .2 .18 \pm 0.83), \mathrm{p}=0.024$. Volume of urine output was also significantly more in nifedipine group $(94.90 \pm 1.84 \mathrm{ml})$ at 1 hour and thereafter till 24 hour of treatment in comparison to IV labetalol $(41.28 \pm 2.14 \mathrm{ml}), \mathrm{p}=0.000$. Side effects are few and not serious. No patient required crossover treatment.

Conclusions: Both the drugs are equally effective in controlling acute hypertensive emergencies of pregnancy, however oral nifedipine is more rapid in controlling severe hypertension and also it is associated with significantly increased urine output.
\end{abstract}

Keywords: Labetalol, Nifedipine, Severe hypertension

\section{INTRODUCTION}

Hypertensive disorders of pregnancy accounts for $5 \%$ to $10 \%$ of all pregnancies, and together they are one member of the deadly triad - along with hemorrhage and infection. ${ }^{1}$ According to World Health Organization at least a woman dies every seven minutes from complications of hypertensive disorders of pregnancy. ${ }^{2}$ Prevalence of hypertensive disorders of pregnancy was
$7.8 \%$ with preeclampsia in $5.4 \%$ of the study population in India. ${ }^{3}$ In several worldwide studies reviewed by Staff and co-workers (2015), the incidence of preeclampsia in a nulliparous woman ranges from 3 to 10 percent while in multiparous it ranges from 1.4 to 4 percent. $^{4}$

National institute for health and clinical excellence has defined severe hypertension in pregnancy as diastolic blood pressure $110 \mathrm{mmHg}$ or greater, systolic blood 
pressure $160 \mathrm{mmHg}$ or greater. $^{5}$ Severe preeclampsia/eclampsia with blood pressure reading $\geq 160 / 110 \mathrm{mmHg}$ is associated with increased risk of complications like placental abruption, pulmonary edema, hypertensive encephalopathy, intracranial hemorrhage, eclampsia and other end organ damage with poor perinatal outcome. The reduction of blood pressure to levels $\leq 150 / 100 \mathrm{mmHg}$ is necessary to reduce these complications.

Several drugs are available to rapidly lower blood pressure in case of hypertensive emergencies of pregnancy. The three most commonly employed are hydralazine, labetalol and nifedipine. All three of these are recommended as first line agents. ${ }^{6}$ Hydralazine is still probably the most commonly used antihypertensive in United States of America in managing severe hypertension of pregnancy. Studies comparing hydralazine to labetalol and nifedipine for the treatment of severe hypertension found that hydralazine was associated with a higher incidence of adverse outcomes like hypotension, placental abruption, caesarean section, oliguria, adverse effect on fetal heart rate, low apgar score at 1 minute, when compared to other antihypertensives. ${ }^{7}$ Nifedipine has now been used safely in a number of obstetric trials for the treatment of hypertensive emergencies. ${ }^{8-11}$ It is orally effective, cheap, easy to administer and store as well. Nifedipine increases cardiac output and coronary blood flow. It also increases urine output. Intravenous labetalol is equally effective in controlling severe hypertension in pregnancy and has the advantage of using in unconscious patient

Vermillion et al, in their double blind trial concluded that either drugs are effective in controlling severe hypertension but nifedipine reduces blood pressure more rapidly. ${ }^{12}$ Dhali $\mathrm{B}$ et al, in their study revealed that nifedipine achieved the therapeutic goal blood pressure $(\leq 150 / 100 \mathrm{mmHg})$ more rapidly as compared to intravenous labetalol. ${ }^{13}$ Raheem IA et al. in their study concluded that both regimens are rapidly effective in controlling the severe hypertension in pregnancy. ${ }^{14} \mathrm{~S}$. Shekhar and co. in a meta-analysis concluded that oral nifedipine is as efficacious and safe as intravenous labetalol and may have an edge in low resource setting. ${ }^{15}$

The aim of the our study is to compare the two most commonly used drugs, oral nifedipine and IV labetalol in terms of time taken to achieve the target blood pressure, number of dosage required, adverse effects and maternal and perinatal outcomes.

\section{METHODS}

This randomized controlled trial study was carried out in the Department of Obstetrics and Gynecology, Assam Medical College and Hospital, Dibrugarh for a period of one year from $1^{\text {st }}$ July 2017 to $30^{\text {th }}$ June 2018 . A total of 80 pregnant women more than 20 weeks of gestation with blood pressure reading $\geq 160 / 110 \mathrm{mmHg}$ were enrolled in the study who fulfilled the inclusion criteria.

Pregnant women more than 20 weeks of gestation with blood pressure reading $\geq 160 / 110 \mathrm{mmHg}$ and medical decision to control blood pressure rapidly were included for the study.

Patients with essential hypertension, history of cardiac disease, bronchial asthma, hematological disorder, allergy to labetalol or nifedipine, diabetes mellitus and liver diseases were excluded. Maternal heart rate $<60$ or $>120$ beats per minute and patient refused to participate in the study were also excluded.

After admission patients were counseled and informed and written consent was taken. A thorough history was taken. A detailed general, systemic and obstetric examination was carried out. Blood pressure was measured with conventional mercury sphygmomanometer in sitting position, in the left arm. Appearance of the first heart sound (K1) and complete disappearance of the sounds (K5) were accepted as systolic and diastolic blood pressure, respectively. Patients were catheterized with Foley's catheter to measure the volume of urine output. Necessary laboratory investigations (complete blood count including platelet count, random blood sugar, blood grouping and cross matching, liver and renal function tests, serum LDH and uric acid, urine for albumin and ultrasonography were done.

Assessment of fetal wellbeing was carried out by clinical (fetal kick count, FHR) and ultrasonic evaluation (BPP). Antenatal corticosteroids were administered for lung maturity in women with less than 34 weeks gestation. Antenatal magnesium sulphate was administered to the women as per the hospital protocol.

Patients were randomly allocated into two groups based on computer generated random numbers, 40 patients in each groups, Group A or labetalol group (study group) and Group B or nifedipine group (control group). Women were randomly assigned to be started either with intravenous labetalol (study group) or oral nifedipine (control group) until satisfactory BP control was achieved $(\leq 150 / 100 \mathrm{mmHg})$.

- Study group (Group A): They were administered intravenous injection labetalol in an escalating dose regimen of $20 \mathrm{mg}, 40 \mathrm{mg}, 80 \mathrm{mg}, 80 \mathrm{mg}$ and $80 \mathrm{mg}$, every 15 minutes, up to $300 \mathrm{mg}$ till the target blood pressure was achieved, i.e. $\leq 150 / 100 \mathrm{mmHg}$.

- Control group (Group B): They were administered capsule nifedipine $10 \mathrm{mg}$ orally, every 15 minutes, till target BP was achieved, i.e. $\leq 150 / 100 \mathrm{mmHg}$.

During the study period maternal blood pressures was recorded at every fifteen minutes interval till achievement of target blood pressure $(\leq 150 / 100 \mathrm{mmHg})$, then every 
thirty minutes for next 2 hours then every hourly till the BP was settled. After successful control of blood pressure, further antihypertensive therapy was started two hours after the last study drug administration. In case of treatment failure (blood pressure not decreasing with maximum dose of either drug), drug regime was to be crossed over. Continuous maternal vital parameters and fetal wellbeing were monitored all throughout the monitoring period and for another two hours.

Depending upon the maternal and fetal conditions termination of pregnancy was expedited. If Bishop's score was less than 6 , induction of labor was done with intra-cervical PGE2 gel. If score was 6 or more, artificial membrane rupture was done. Syntocinon augmentation was done depending upon the condition. Cesarean section was carried out depending on maternal/fetal indications and in cases of failed induction. Modified WHO partograph was maintained to record labour events. Delivery was attended by the pediatrician also. During the course of the study maternal and fetal heart rate was recorded every 15 minutes. Urine output was recorded at the end of the first hour of the study and continued thereafter. Maternal side effects profile of the drugs and complications during and after the study were recorded. Perinatal outcome measures like birth weight, still birth, neonatal death, 1 and 5 minute Apgar score and NICU admissions were recorded.

After completion of the drug trial, patients were provided with a questionnaire with yes or no answers on the symptoms of nausea, vomiting, palpitation, dizziness, headache, and shortness of breath experienced during the study course.
The primary outcome of this study was the time taken and number of dose required to achieve a target blood pressure of $\leq 150 / 100 \mathrm{mmHg}$, in both the groups. Both systolic and diastolic target blood pressure had to be achieved. The secondary outcome measures included volume of urine output, any fetal heart rate abnormality, and maternal heart rate profile in the first hour, maternal complications (placental abruption, eclampsia, hypotension, and strokes), side effect profile of the drugs and perinatal outcome measures.

\section{Statistical analysis}

Data analysis was done by using SPSS 16 software. Data were presented in terms of percentages, proportions, mean $\pm \mathrm{SD}$, median (inter-quartile range). Chi-square test, t-test, Mann-Whitney U-test were applied (whichever applicable) to find out statistical significance. A ' $p$ 'value of $<0.05$ was considered statistically significant.

\section{RESULTS}

Group A received intravenous labetalol and Group B received oral nifedipine. The baseline characteristics like maternal age, gravidity, parity, socioeconomic status, educational qualifications, locality, booked/unbooked status, gestational age, BMI, proteinuria, maternal heart rate at the beginning of the treatment and systolic and diastolic blood pressure at the beginning of the study were comparable in both the groups (Table 1).

Table 1: Baseline characteristics of participants randomized to intravenous Labetalol or oral Nifedipine for acute blood pressure control in hypertensive emergencies of pregnancy.

\begin{tabular}{|c|c|c|c|c|}
\hline \multicolumn{2}{|l|}{ Characteristics } & $\begin{array}{l}\text { Group-A Labetalol } \\
(\mathrm{n}=\mathbf{4 0})\end{array}$ & $\begin{array}{l}\text { Group-B Nifedipine } \\
(\mathrm{n}=\mathbf{4 0})\end{array}$ & $p$ value \\
\hline \multicolumn{2}{|c|}{ Age (years), Mean \pm SD } & $25.28 \pm 4.87$ & $24.68 \pm 5.03$ & 0.589 \\
\hline \multicolumn{2}{|l|}{ Primigravida $(\%)$} & 67.5 & 72.5 & \multirow{2}{*}{0.626} \\
\hline \multicolumn{2}{|l|}{ Multigravida (\%) } & 32.5 & 27.5 & \\
\hline \multicolumn{2}{|c|}{ Gestational weeks, Mean \pm SD } & $35.88 \pm 2.43$ & $36.05 \pm 2.12$ & 0.733 \\
\hline \multirow{2}{*}{ Booking Status (\%) } & Booked & 60.0 & 65.0 & \multirow{2}{*}{0.817} \\
\hline & Unbooked & 40.0 & 35.0 & \\
\hline \multirow{4}{*}{ BMI $(\%)$} & Underweight $(<18.5)$ & 2.5 & 5.0 & \multirow{4}{*}{0.917} \\
\hline & Normal (18.5 to 24.9$)$ & 12.5 & 10.0 & \\
\hline & Overweight (25 to 29.9$)$ & 27.5 & 30.0 & \\
\hline & Obesity (30 and above) & 57.5 & 55.0 & \\
\hline \multicolumn{2}{|c|}{ Systolic BP (mmHg), Mean \pm SD } & $174.45 \pm 7.50$ & $175.80 \pm 7.72$ & 0.430 \\
\hline \multicolumn{2}{|c|}{ Diastolic BP (mmHg), Mean \pm SD } & $115.35 \pm 3.12$ & $115.20 \pm 3.03$ & 0.828 \\
\hline \multicolumn{2}{|c|}{ Heart Rate (Beats/min), Median (Range) } & $80(76-88)$ & $79(72-88)$ & 0.478 \\
\hline \multirow{4}{*}{ Proteinuria $(\%)$} & $1+$ & 27.5 & 25.0 & \multirow{4}{*}{0.966} \\
\hline & $2+$ & 10.0 & 7.5 & \\
\hline & $3+$ & 10.0 & 10.0 & \\
\hline & No Proteinuria & 52.5 & 57.5 & \\
\hline \multirow{2}{*}{$\begin{array}{l}\text { Inj. Magnesium } \\
\text { sulphate given }(\%)\end{array}$} & Yes & 20.0 & 17.5 & \multirow{2}{*}{1.000} \\
\hline & No & 80.0 & 82.5 & \\
\hline
\end{tabular}


In the present study, oral nifedipine achieved target blood pressure more rapidly than intravenous labetalol (26.25 \pm 12.60 minutes versus $32.62 \pm 12.19$ minutes, $\mathrm{p}=$ $0.024)$. Majority of the patients $(45 \%)$ in nifedipine group achieved their target blood pressure in 15 minutes of commencing antihypertensive therapy while majority of the patients (55\%) in labetalol group took 30 minutes to achieve their target blood pressure. None of the patients in either group took more than 60 minutes to achieve target BP.
In the present study, mean number of doses required to achieve target BP in Group A was $2.18(0.813)$ and in Group B it was $1.75(0.840)$ with $\mathrm{p}$ value 0.024 , which is statistically significant. So, oral nifedipine took significantly less number of doses in achieving target BP in comparison to intravenous labetalol. No patients in either group took more than 4 doses to achieve their target $\mathrm{BP}$, so crossover treatment was not required.

Table 2: Outcomes of randomized trial of intravenous Labetalol versus oral Nifedipine for acute blood pressure control in hypertensive emergencies of pregnancy.

\begin{tabular}{|c|c|c|c|c|c|}
\hline \multicolumn{3}{|c|}{ Primary outcome } & $\begin{array}{l}\text { Group-A Labetalol } \\
(n=40)\end{array}$ & $\begin{array}{l}\text { Group-B Nifedipine } \\
(n=40)\end{array}$ & p value \\
\hline \multicolumn{3}{|c|}{$\begin{array}{l}\text { Time (minutes) taken to achieve blood pressure } \\
\leq 150 / 100 \mathrm{mmHg} \text {, Mean } \pm \text { SD }\end{array}$} & $32.62 \pm 12.19$ & $26.25 \pm 12.60$ & 0.024 \\
\hline \multicolumn{3}{|c|}{$\begin{array}{l}\text { Total antihypertensive doses to achieve blood pressure } \\
\leq 150 / 100 \mathrm{mmHg} \text {, Mean } \pm \text { SD }\end{array}$} & $2.18 \pm 0.83$ & $1.75 \pm 0.84$ & 0.024 \\
\hline \multicolumn{6}{|c|}{ Secondary Outcomes } \\
\hline \multirow{2}{*}{\multicolumn{2}{|c|}{ Mode of delivery $(\%)$}} & Vaginal & 70.0 & 72.5 & \multirow{2}{*}{0.805} \\
\hline & & Caesarean & 30.0 & 27.5 & \\
\hline \multicolumn{3}{|c|}{ Birth weight $(\mathrm{kg})$, Mean \pm SD } & $2.208 \pm 0.53$ & $2.29 \pm 0.48$ & 0.887 \\
\hline \multirow{2}{*}{\multicolumn{2}{|c|}{$\begin{array}{l}\text { Neonatal intensive care } \\
\text { admission }(\%)\end{array}$}} & Yes & 27.5 & 17.5 & \multirow{2}{*}{0.422} \\
\hline & & No & 72.5 & 82.5 & \\
\hline \multirow{2}{*}{\multicolumn{2}{|c|}{$\begin{array}{l}\text { Apgar Score at } 5 \text { minutes } \\
(\%)\end{array}$}} & $\leq 7$ & 15.0 & 12.5 & \multirow{2}{*}{0.745} \\
\hline & & $>7$ & 85.0 & 87.5 & \\
\hline \multirow{3}{*}{$\begin{array}{l}\text { Neonatal } \\
\text { outcome } \\
(\%)\end{array}$} & \multicolumn{2}{|c|}{ Live birth } & 100.0 & 97.5 & \multirow{3}{*}{1.000} \\
\hline & \multicolumn{2}{|c|}{ Still birth } & 0 & 2.5 & \\
\hline & \multicolumn{2}{|c|}{ Neonatal death } & 5.0 & 2.5 & \\
\hline \multirow{6}{*}{$\begin{array}{l}\text { Reported side } \\
\text { effects }(\%)\end{array}$} & \multicolumn{2}{|c|}{ No adverse effect } & 80.0 & 87.5 & \multirow{6}{*}{0.629} \\
\hline & \multicolumn{2}{|c|}{ Nausea } & 5.0 & 0 & \\
\hline & \multicolumn{2}{|c|}{ Vomiting } & 2.5 & 0 & \\
\hline & \multicolumn{2}{|c|}{ Dizziness } & 5.0 & 2.5 & \\
\hline & \multicolumn{2}{|c|}{ Palpitation } & 0 & 2.5 & \\
\hline & \multicolumn{2}{|c|}{ Headache } & 7.5 & 7.5 & \\
\hline \multirow{2}{*}{\multicolumn{2}{|c|}{$\begin{array}{l}\text { Maternal complications } \\
\text { during and after treatment } \\
(\%)\end{array}$}} & Eclampsia & 5.0 & 2.5 & \multirow[b]{2}{*}{0.8} \\
\hline & & Placental abruption & 2.5 & 2.5 & \\
\hline
\end{tabular}

Table 3: Cumulative urine output of participants randomized to intravenous Labetalol or oral Nifedipine for acute blood pressure control in hypertensive emergencies of pregnancy.

\begin{tabular}{|llll|}
\hline Duration (hours) & $\begin{array}{l}\text { Cumulative urine output }(\mathrm{ml}) \\
\text { Labetalol (Mean+SD) } \\
(\mathbf{n = 4 0 )}\end{array}$ & $\begin{array}{l}\text { Nifedipine (Mean } \pm \text { SD) } \\
(\mathbf{n = 4 0})\end{array}$ & p value \\
\hline 1 & $41.28 \pm 2.14$ & $94.90 \pm 1.84$ & $<0.0001$ \\
\hline 4 & $403.20 \pm 3.77$ & $703.78 \pm 4.44$ & $<0.0001$ \\
\hline 8 & $744.10 \pm 3.94$ & $1153 \pm 3.77$ & $<0.0001$ \\
\hline 16 & $1003.65 \pm 4.39$ & $1597.40 \pm 13.96$ & $<0.0001$ \\
\hline 24 & $1455.12 \pm 3.66$ & $2501.20 \pm 7.84$ & $<0.0001$ \\
\hline
\end{tabular}

In Group A majority of the patient (55\%) took 2 doses to achieve the target BP while in Group B, majority of the (45\%) patients took only 1 dose to achieve the target BP.
Cumulative volume of urine output were significantly more in those patients receiving oral nifedipine than those 
with IV labetalol recorded in 1, 4, 8, 16 and 24 hours of starting treatment (shown in Table 3).

In Group A the results of the ANOVA indicated that there is no significant changes in Maternal Heart rate with time effect $(p=0.709)$ but in Group B there is a significant changes in Maternal Heart rate with time effect $(p=0.000)$. Follow-up comparison indicated that each pair-wise differences was also significant $(\mathrm{p}=$ 0.000).

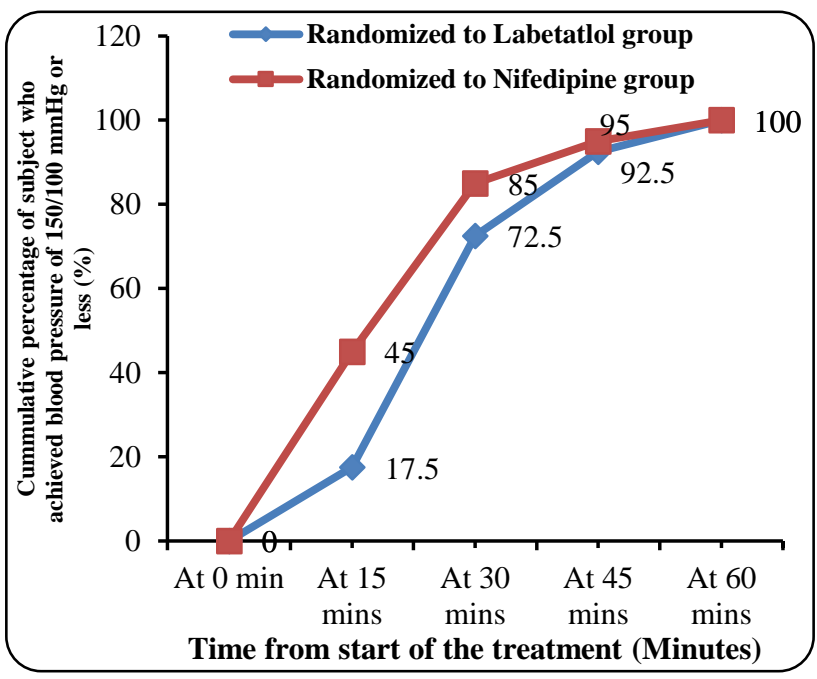

Figure 1: Cumulative percentage of subjects who achieved target blood pressure during treatment.

A total of 7 patients ( 3 in labetalol group and 4 in nifedipine group) had fetal heart rate abnormalities (bradycardia) during the treatment period though not statistically insignificant.

In Group A, 5\% and in Group B, 2.5\% patients developed antepartum eclampsia after the completion of treatment. One $(2.5 \%)$ patient in each group had placental abruption after the completion of the treatment. No patients developed hypotension or stroke.

Neonatal outcomes were comparable in both the groups. $6(15 \%)$ in labetalol group and $5(12.5 \%)$ babies in nifedipini group, had an APGAR score of $\leq 7$ at 5 minutes of birth.

No serious adverse effects were seen in either group during the course of the treatment. Intergroup difference of adverse effects was not statistically significant.

\section{DISCUSSION}

Oral nifedipine achieved target BP $(\leq 150 / 100 \mathrm{mmHg})$ more rapidly in 26.25 \pm 12.60 minutes (Mean \pm SD), in comparison to $32.62 \pm 12.19$ minutes (Mean \pm SD) with IV labetalol, $(\mathrm{p}=0.024)$. Study conducted by Vermillion et al.12 found that nifedipine took significantly less time (mean \pm SD, 25 \pm 13.6 minutes) in comparison to labetalol group (43.6 \pm 25.4 minutes; $\mathrm{P}=0.002)$ in achieving the target BP. In many other studies like that conducted by Sujit et al, Shekhar et al, Gavit Y et al, showed that nifedipine took significantly less time in achieving the target BP. ${ }^{16-18}$

Oral nifedipine group also required less number of doses to achieve the target $\mathrm{BP}$ in comparison to IV labetalol $(1.75 \pm 0.840$ vs. $2.18 \pm 0.83), p=0.024$. However, both the drugs were successful in achieving the target blood pressure within the study period and so no patients required crossover treatment. Sujit et al, in their study, found that nifedipine group had required in average $1.12 \pm .32$ doses and the labetalol group 2.04 \pm 1.37 doses to achieve the target $\mathrm{BP}$ which is statistically highly significant (' $\mathrm{P}$ ' value $<0.01$ ). ${ }^{16}$ Shekhar et al, also noted that significantly less number of doses of nifedipine was required to achieve target blood pressure compared to labetalol. ${ }^{17}$ Vermillion et al, and Gavit $\mathrm{Y}$ et al, in their studies reported $100 \%$ success rate to achieve the target blood pressure with both drugs. ${ }^{12,18}$

In the present study, it is evident that volume of urine output, in patients treated with oral nifedipine was significantly higher at the end of the first hour of treatment in comparison to intravenous labetalol; significantly increased urine output in nifedipine group persisted at least till 24 hours after the commencement of the treatment. Barton $\mathrm{J}$ et al, and Dhali B et al in their studies reported similar significant increase in urine output in nifedipine group. ${ }^{13,19}$

In the present study it is seen that mean maternal heart rate was progressively increased in Group $\mathrm{B}$ which is statistically significant. Mean \pm SD maternal heart rate was 80.3 (9.19) beats/minute at the start of the treatment and it was increasing; at 60 minute of treatment it was 97.70 (3.86) beats/minute. In Group A, mean $( \pm$ SD) maternal heart rate at the beginning of the study was $81.65(9.41)$ beats/minute and at 60 minutes of treatment it was 80.75 (9.81) beats/minute. So, heart rate decreased but was not statistically significant in Group A. Raheem IA et al, in their study recorded similar significant increase in maternal heart rate in nifedipine group. ${ }^{14}$

In the present study, $7.5 \%$ patient in Labetalol Group and $10 \%$ in Nifedipine Group had FHR abnormalities with statistically insignificant intergroup difference. Dhali B et al, in their study reported similar findings of FHR abnormalities; $6 \%$ and $12 \%$ respectively. ${ }^{13}$

There were very few maternal complications seen during the study period. Eclampsia was seen in $2(5 \%)$ patients in labetalol group and $1(2.5 \%)$ patient in nifedipine group. Dhali B et al, in their study recorded similar percentage of eclampsia; $6 \%$ and $2 \%$ respectively. ${ }^{13}$ Placental abruption was found in $1(2.5 \%)$ patient in each group, similar to the study conducted by Sujit et al. ${ }^{16}$ 
In the present study, mean (SD) birth weight of babies in both the groups were comparable, similar to the study Kumari RV et al. ${ }^{20}$ There was only one stillbirth (placental abruption). Neonatal death was 5\% in Group A and $2.5 \%$ in Group B. All the neonatal death occurred due to complications of prematurity though not statistically significant. Sujit et al, Dr Das S et al, and Padmaja A et al. also recorded comparable perinatal death. ${ }^{16,21,22}$

$15 \%$ in babies Group A and $12.5 \%$ in Group B had 5 minute Apgar score $\leq 7$. All the babies with low Apgar score subsequently discharged successfully. The present study is comparable to study conducted by Das $\mathrm{S}$ et al, where 5 minute Apgar score $\leq 7$ was $10 \%$ in labetalol group and $8 \%$ in nifedipine group. ${ }^{21}$

NICU admission was slightly higher in labetalol group through statistically not significant. Our study is comparable to study conducted by Kumari RV et al. ${ }^{20}$

In the present study, no serious and only few adverse effects were noted, so both the drugs appeared to be safe. Adverse effects profile of the present study was comparable with the study conducted by Raheem IA et al. $^{14}$

\section{CONCLUSION}

Hypertensive disorders of pregnancy is one of the most common causes of high maternal death in India and globally as well.

The present study shows that both labetalol and nifedipine are equally effective in controlling acute rise in blood pressure with no serious side effects, however oral nifedipine reduced the blood pressure more rapidly in comparison to intravenous labetalol. Also, patients treated with nifedipine showed increased urine output in comparison to labetalol. Neither of the drugs was associated with any hazardous effect on maternal and perinatal outcomes.

To conclude, our study recommends that, both the drugs can be used as first line antihypertensive agents in acute control of hypertensive emergencies of pregnancy depending upon the clinician's familiarity and choice of the drugs, but oral nifedipine is preferable to intravenous labetalol as its use is more convenient and associated with better urine output. Large scale studies are required to definitively establish the superiority of the drugs over each other.

\section{ACKNOWLEDGMENTS}

Authors would like to thank the colleagues and staffs of the department of obstetrics and gynecology, Assam Medical College and Hospital, Dibrugarh for their assistance in completing this study.
Funding: No funding sources

Conflict of interest: None declared

Ethical approval: The study was approved by the Institutional Ethics Committee

\section{REFERENCES}

1. Martin JN, Owens My, Keiser SD. Standardized Mississipi protocol treatment of 190 patients with HELLP syndrome: slowing disease progression and preventing new major maternal morbidity. Hypertens Pregnancy. 2012;31(1):79.

2. Von Dadelszen P, Magee L. What matters in preeclampsia is the associated adverse outcomes: the view from Canada. Current opinion in obstetrics and gynecology. 2008;20(2):110-5.

3. Sajith M, Nimbargi V, Modi A, Sumariya R, Pawar A. Incidence of pregnancy induced hypertension and prescription pattern of antihypertensive drugs in pregnancy. International Journal of Pharma Sciences and Research. 2014;5(4).

4. Fisher S, Roberts JM. The placenta in normal pregnancy and preeclampsia. In Taylor RN, Roberts JM, Cunningham FG (eds): Chesley's Hypertensive Disorders in Pregnancy, $4^{\text {th }}$ Ed. Amsterdam, Academic Press; 2015.

5. Lo JO, Mission JF, Caughey AB. Hypertensive disease of pregnancy and maternal mortality. Curr Opin Obstet Gynecol. 2013. [Epub ahead of print]

6. American College of Obstetricians and Gynecologists: Emergent therapy for acute onset, severe hypertension during pregnancy and the postpartum period. Committee Opinion No. 692, April 2017a.

7. Magee LA, Cham C, Waterman EJ. Hydralazine for treatment of severe hypertension in pregnancy: metaanalysis. BMJ. 2003;327(7421):955-60.

8. Barton J, Hiett A, Conover W. The use of nifedipine during the postpartum period in patients with severe preeclampsia. Am J Obtet Gynecol. 1990;162:78892.

9. Fenakel K, Fenakel G, Appelman Z, Lurie S, KatzZ, Shoham Z. Nifedipine in the treatment ofsevere preeclampsia. Obstet Gynecol. 1991;77:331-7.

10. Scardo JA, Vermillion ST, Hogg B, Newman RB. Hemodynamic effects of oral nifedipine in preeclamptic hypertensive emergencies. Am J Obstet Gynecol. 1996;175:336-8.

11. Seabe SJ, Moodley J, Becker P. Nifedipine in acute hypertensive emergencies in pregnancy. S Afr Med J. 1989;76:248-50.

12. Vermillion ST, Scardo JA, Newman RB, Chauhan SP. A randomized, double-blind trial of oral nifedipine and intravenous labetalol in hypertensive emergencies of pregnancy. Am J Obstet Gynecol. 1999;181:858-61.

13. Dhali B, Bhattacharya S, Ganguly RP, Bandyopadhyay S, Mondal M, Dutta M, et al. A randomized trial of intravenous labetalol and oral nifedipine in severe pregnancy induced hypertension. 
Int J Reprod Contracept Obstet Gynecol. 2012;1:426.

14. Raheem IA, Saaid R, Omar SZ, Tan PC. Oral nifedipine versus intravenous labetalol for acute blood pressure control in hypertensive emergencies of pregnancy: a randomised trial. Available at: www.bjog.org.

15. Shekhar S, Gupta N, Kirubakaran R, Pareek P. Oral nifedipine versus intravenous labetalol for severe hypertension during pregnancy: a systematic review and meta-analysis. BJOG. 2016;123:40-7.

16. Devi SR, Devi RKP, Kumar LA, Devi R, Das S, Deepthambika, et al. Comparative study between oral nifedipine and intravenous labetalol in management of severe pregnancy induced hypertension. European Journal of Pharmaceutical and Medical Research. EJPMR. 2017;4(9):291-6.

17. Shekhar S, Sharma C, Thakur S, Verma S. Oral Nifedipine or Intravenous Labetalol for hypertensive emergency in pregnancy: a randomized controlled trial. Obstet Gynecol. 2013;122(5):1057-63.

18. Gavit Y, Sharma D, Dixit PV. A comparative study of oral nifedipine and intravenous labetalol in control of acute hypertension in severe pre-eclampsia and eclampsia. International Journal of Reproduction, Contraception, Obstet Gynecol. 2018;7(2):719-24.
19. Barton J, Hiett A, Conover W. The use of nifedipine during the postpartum period in patients with severe preeclampsia. Am J Obtet Gynecol. 1990;162:78892.

20. Kumari VR, Saraswathi K, Srilaxmi A. Oral nifedipine versus intravenous labetalol for control of blood pressure in severe preeclampsia. J Evolution Med Dent Sci. 2016;5(20):994-7.

21. Swapan D, Swagata B, Prakash D, Biswajit M. Comparative study of intravenous Labetalol and oral Nifedipine for control of blood pressure in severe preeclampsia. IOSR J Dental Med Sci. 2015;14(10):22-7.

22. Padmaja A, Sravanthi VL. A study of oral Nifedipine and intravenous Labetalol in severe hypertension in pregnancy at teaching hospital. IAIM. 2017;4(8):129.

Cite this article as: Alam A, Zakaria SMA. Oral nifedipine versus intravenous labetalol for acute blood pressure control in hypertensive emergencies of pregnancy: a randomized controlled trial. Int $\mathbf{J}$ Reprod Contracept Obstet Gynecol 2019;8:1921-7. 